EDITORIAL

\title{
HGNC nomenclature for fusion genes
}

(c) The Author(s), under exclusive licence to Springer Nature Limited 2021

Leukemia (2021) 35:3039; https://doi.org/10.1038/s41375-02101437-5

Readers of LEUKEMIA will know the fusion gene created by juxtaposing $B C R$ to $A B L 1$ by chromosome translocation causes chronic myeloid leukemia (CML), some cases of acute lymphoblastic leukemia (ALL) and rare cases of acute myeloid leukemia (AML). Similarly, juxtaposition of $I G H$ and $M Y C$ is the driver mutation of some lymphomas. What is controversial is how these fusion genes should be designated. Until now the nomenclature varied with each scientist choosing their favorite designator, mostly a backward slash (/) or hyphen (-). In the typescript by Bruford and co-workers in this issue of LEUKEMIA [1] a group of experts under auspices of the Human Genome Organization's (HUGO) Gene Nomenclature Committee (HGNC) proposes using double colons (::) as the official designation for fusion genes. These may be written in italics or not, Examples are $B C R:: A B L 1$ and IGH::MYC. BCR, ABL1, IGH and MYC as human genes are always written in capitals and italics without additional symbols or punctuation. HGNC also proposes these gene juxtapositions be termed fusion genes. Other designations, some preferred by students of ancient Greek or orientated to haemopoietic cell transplants such as chimeric genes, are also acceptable.

As LEUKEMIA Editors we strongly support the HGNC recommendation and request authours use the HGNC nomenclature in future submissions to LEUKEMIA and other journals. The goal of HUGO and HGNC is to provide unique symbols and names for human gene loci including protein coding genes, non-coding RNA genes and pseudogenes with the purpose of unambiguous scientific communication. Surely a noble objective.

Robert Peter Gale ${ }^{1,5 凶}{ }^{凶}$, Andreas Hochhaus ${ }^{2,5}$ Nicholas C. P. Cross (DD ${ }^{3,5}$ and Christine J. Harrison ${ }^{4,5}$ ${ }^{1}$ Centre for Haematology Research, Department of Immunology and Inflammation, Imperial College London, London, UK. ${ }^{2}$ Klinik für Innere

Medizin II, Universitätsklinikum Jena, Friedrich-Schiller-Universität Jena, Jena, Germany. ${ }^{3}$ Wessex Regional Genetics Laboratory,

Salisbury, United Kingdom and Faculty of Medicine, University of Southampton, Southampton, United Kingdom. ${ }^{4}$ Translational and Clinical Research Institute, Newcastle University Centre for Cancer, Newcastle-upon-Tyne, England. ${ }^{5}$ The authors contributed equally: Robert Peter Gale, Andreas Hochhaus, Nicholas C. P. Cross, Christine J. Harrison. ${ }^{\circledR}$ email: robertpetergale@alumni.ucla.edu

\section{REFERENCE}

1. Bruford EA, Antonescu CR, Carroll AJ, Chinnaiyan A, Cree IA, Cross NCP, et al. HUGO Gene Nomenclature Committee (HGNC) recommendations for the designation of gene fusions. Leukemia. 2021; https://doi.org/10.1038/s41375-021-01436-6.

\section{ACKNOWLEDGEMENTS}

RPG acknowledges support from the National Institute of Health Research (NIHR) Biomedical Research Centre funding scheme.

\section{COMPETING INTERESTS}

RPG is a consultant to BeiGene Ltd., Fusion Pharma LLC, LaJolla NanoMedical Inc. Mingsight Parmaceuticals Inc., CStone Pharmaceuticals, NexImmune Inc. and Prolacta Bioscience; advisor to Antengene Biotech LLC, Medical Director, FFF Enterprises Inc.; Partner, AZCA Inc.; Board of Directors, Russian Foundation for Cancer Research Support; and Scientific Advisory Board: StemRad Ltd.

\section{ADDITIONAL INFORMATION}

Correspondence and requests for materials should be addressed to Robert Peter Gale.

Reprints and permission information is available at http://www.nature.com/ reprints

Publisher's note Springer Nature remains neutral with regard to jurisdictional claims in published maps and institutional affiliations. 